\title{
Evaluation of the Effect of Empagliflozin Therapy on T Helper 22 Cell-Related Factors in Patients with Type 2 Diabetes Mellitus
}

\author{
Hamid Moghimi1 $^{\text {iD }}$, Shiva Borzouei², Alireza Zamani³, Mahdi Behzad, ${ }^{4}$ * iD \\ ${ }^{I}$ MSc in Immunology, Department of Immunology, School of Medicine, Hamadan University of Medical Sciences, Hamadan, \\ Iran \\ ${ }^{2}$ Associate Professor, Department of Internal Medicine, School of Medicine, Hamadan University of Medical Sciences, \\ Hamadan, Iran \\ 3 Professor, Department of Immunology, School of Medicine, Hamadan University of Medical Sciences, Hamadan, Iran \\ ${ }^{4}$ Associate Professor, Department of Immunology, School of Medicine, Hamadan University of Medical Sciences, Hamadan, \\ Iran \\ * Corresponding Author: Mahdi Behzad, Department of Immunology, School of Medicine, Hamadan University of Medical \\ Sciences, Hamadan, Iran.Email: m.behzad@umsha.ac.ir
}

\begin{tabular}{|c|c|}
\hline & Abstract \\
\hline $\begin{array}{l}\text { Received: } 02.11 .2020 \\
\text { Accepted: } 28.01 .2021\end{array}$ & $\begin{array}{l}\text { Background and Objective: The increased response of Thelper (Th) } 22 \\
\text { cells might be involved in the pathogenesis of Type } 2 \text { Diabetes Mellitus } \\
\text { (T2DM) }\end{array}$ \\
\hline \multirow[t]{2}{*}{$\begin{array}{l}\text { How to Cite this Article: } \\
\text { Moghimi H, Borzouei S, Zamani } \\
\text { A, Behzad M. Evaluation of the } \\
\text { Effect of Empagliflozin Therapy } \\
\text { on T Helper } 22 \text { Cell-Related } \\
\text { Factors in Patients with Type } 2 \\
\text { Diabetes Mellitus. Avicenna J } \\
\text { Clin Med. 2021; 27(4): 193-200. } \\
\text { DOI: } 10.29252 / \text { ajcm.27.4.193 }\end{array}$} & 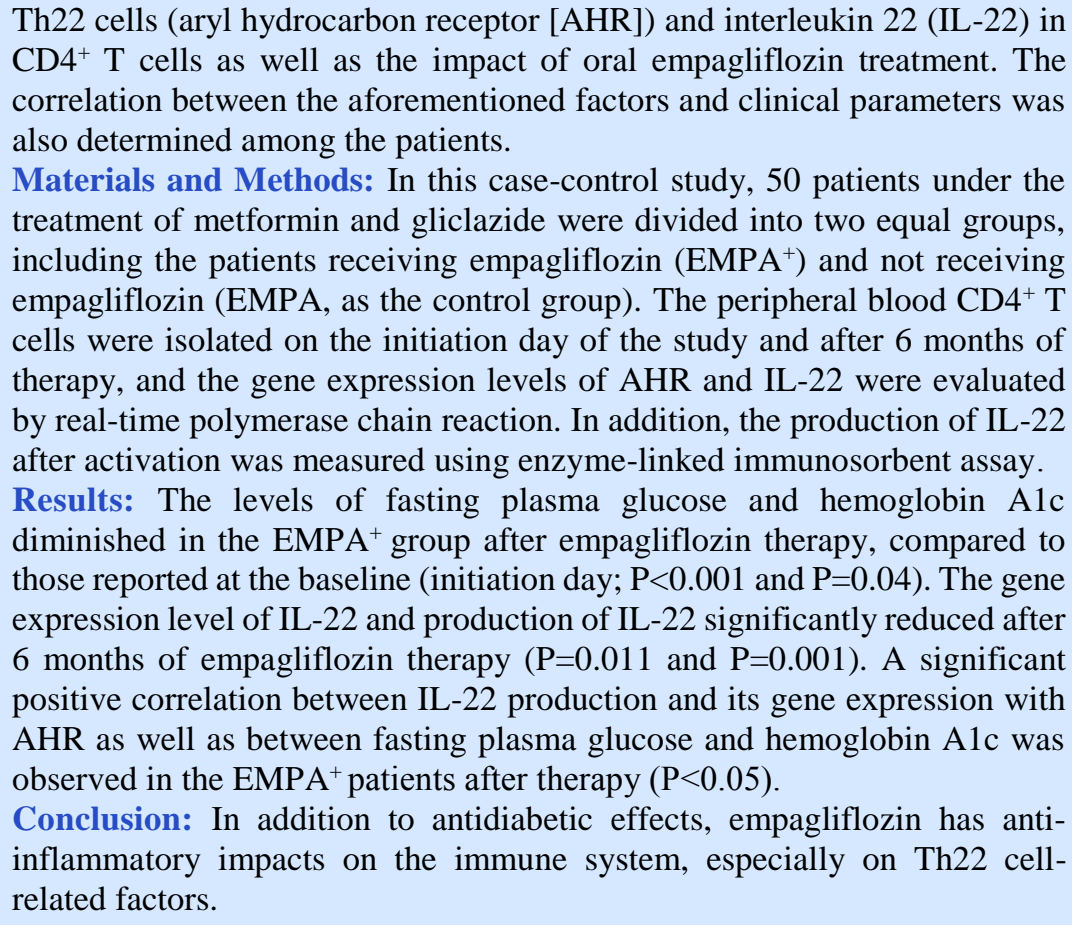 \\
\hline & $\begin{array}{l}\text { Keywords: Diabetes Mellitus Type 2, Empagliflozin, Interleukin 22, T } \\
\text { Helper } 22 \text { Cell }\end{array}$ \\
\hline
\end{tabular}


dof: $10.29252 / \mathrm{ajcm} .27 .4 .193$

\title{
بررسى اثر درمان با امياتليفلوزين بر فاكتور هاى مرتبط با سلولهاى T كمكى Y T در بيماران مبتلابه ديابت شيرين نوع برئ
}

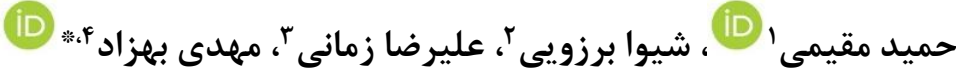 \\ ' كارشناس ارشد، كروه ايمونولوزى، دانشكده يزشكى، دانشكاه علوم يزشكى همدان، همدان، ايران

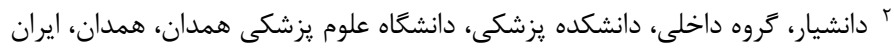

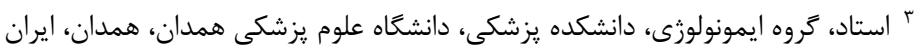

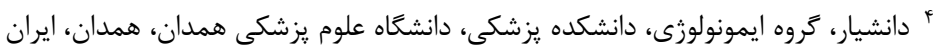 \\ * *ويسنده مسئول: مهدى بهزاد، گروه ايمونولوزى، دانشكده يزشكى، دانشعاه علوم يزشكى همدان، همدان، ايران. \\ ايميل:m.behzad@umsha.ac.ir
}

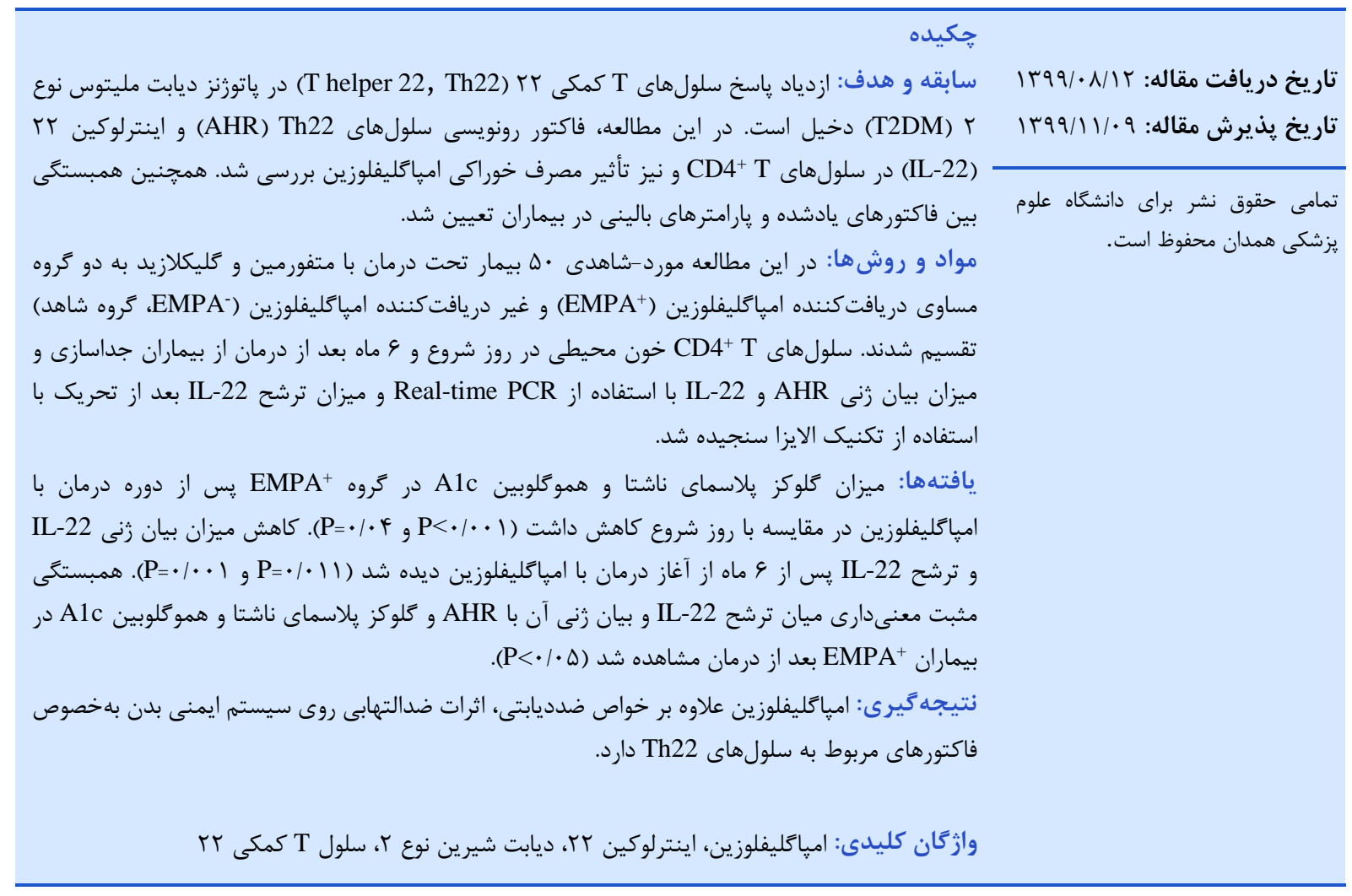

مقدمه

خصوصيات و عملكرد منحصربهفرد آنها به زيرگروههاى

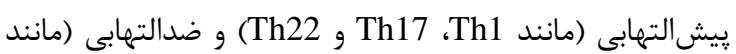

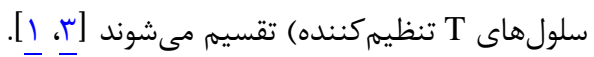
در سيستم ايمنى بدن لنفوسيتهاى Th22 با بيان فاكتور

رونويسى آريل هيدروكربن ( Aril Hydrocarbon Receptor,

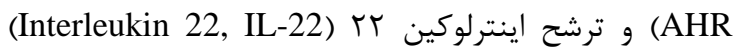

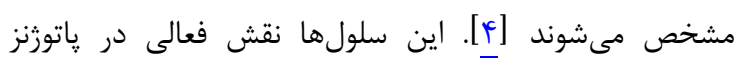
بيمارىهاى خودايمن و التهابى همانند لويوس اريتماتوز، آرتريت
Type 2 diabetes mellitus, ) ديابت شيرين نوع (T2DM با مقادير زياد كلوكز در گردش خون و مقاومت به ( انسولين در بيماران مشخص مىشود و با التهاب مزمن سيستم

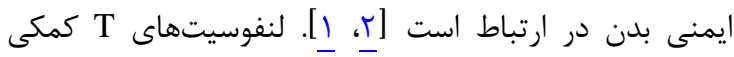
با ماركر CD4 (T helper cells, Th)

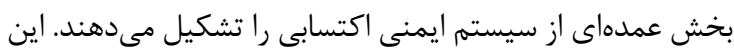

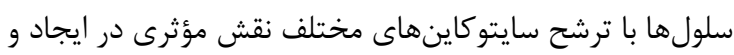

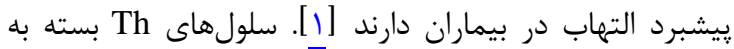


بررسى شد. تعيين همبستگى بين فاكتورهاى بيانشده و يارامترهاى بالينى از اهداف ديكر مطالعه حاضر است.

\section{مواد و روشىها}

در اين مطالعه مورد-شاهدى •ه بيمار مبتلابه T2DM

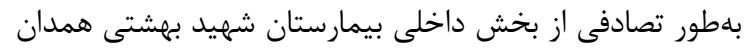

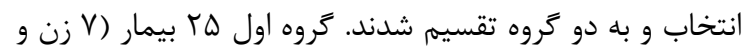

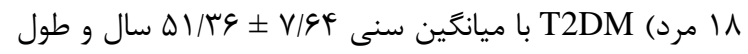

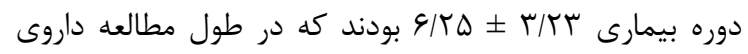

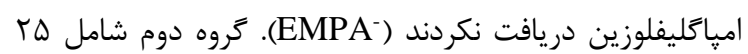

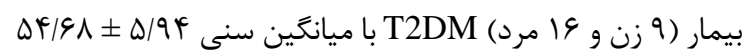

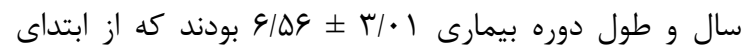

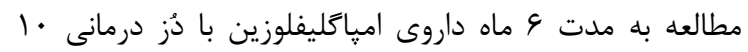
ميلى گرم در روز دريافت كردند.

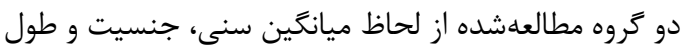

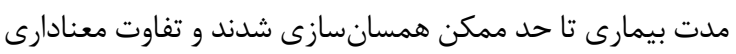

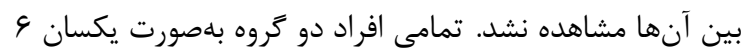

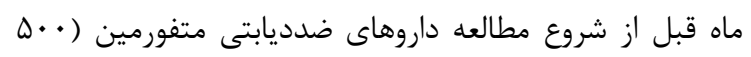

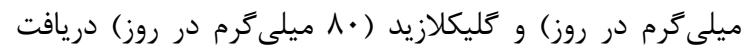

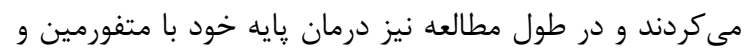

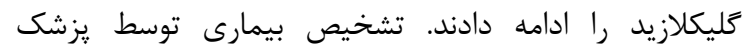

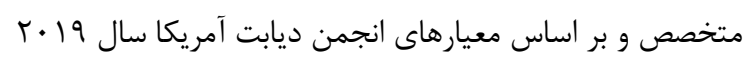

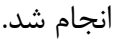

معيارهاى ورود بيماران به مطالعه شامل اين موارد بود: () Fلوكز پيلاسماى ناشتا (Fasting Plasma glucose, FPG)

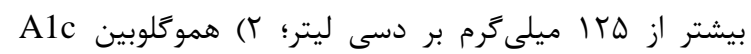
بيشتر از (HbA1c)

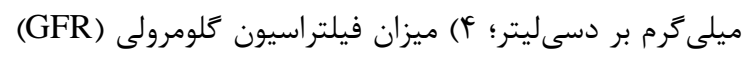

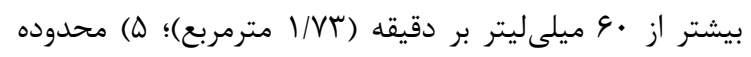

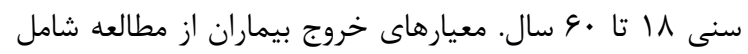

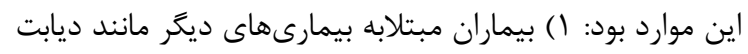

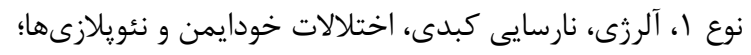

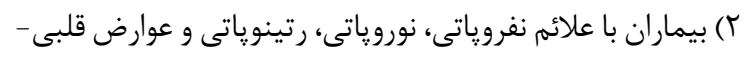

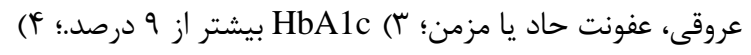

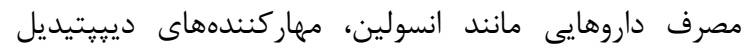

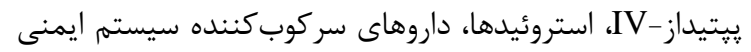
و آنتىبيوتيكها (حداقل \& ماه قبل از شروع مطالعه).

\section{نمونهَيرى و جداسازى سلولهاى /يمنى}

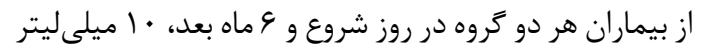

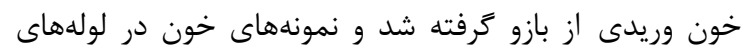

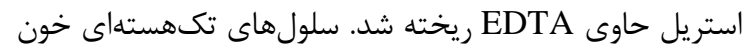
محيطى (Peripheral blood mononuclear cell, PBMCs) با استفاده از روش فايكول (Sigma, Germany) جدا شدند.
روماتوئيت و ديابت مليتوس نوع ا و r ايفا مى كنند؛ بهطور مثال،

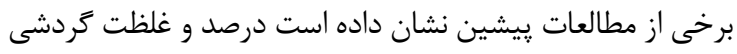

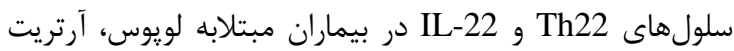

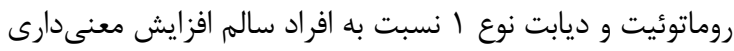

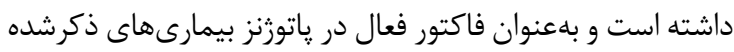

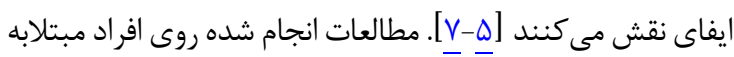
Th22 نشان داده است در پاتورنز بيمارى، سلولهاى T2DM

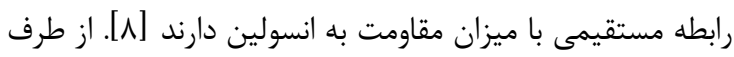
ديغر، فراوانى سلولهاى Th22

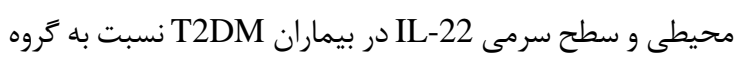

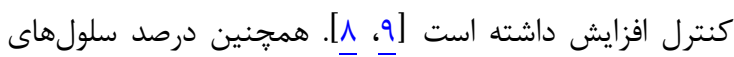
CD4+IL-22+

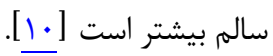

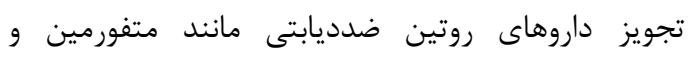
كليكلازيد بهعنوان خط اول درمانى در بيمارى T2DM مطرح

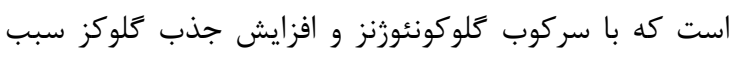

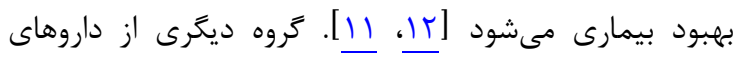

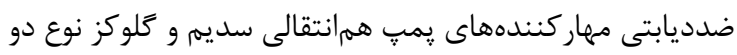
(Sodium glucose cotransporter-2, SGLT2) از مهمترين آنها مىتوان به امياكليفلوزين اشاره كرد كه اخيراً

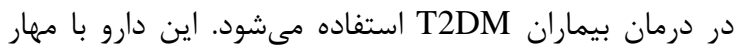

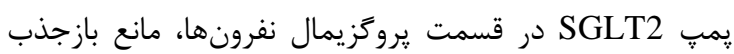
كلوكز دفعى به خون و در مسيرى مستقل از انسولين، باعث

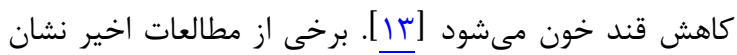
داده است مصرف امياكليفلوزين اثر ضدالتهابى نيز دارد؛ مثان مثلاً

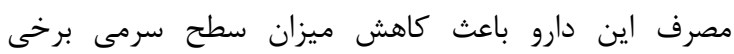

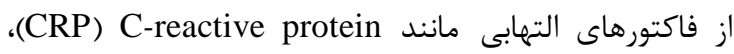
(TNF- $\alpha$ ) Tumor necrosis factor- $\alpha$

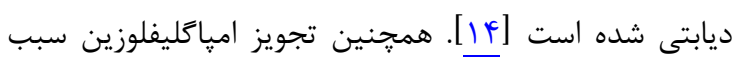
كاهش سطح سرمى CRP و افزايش غلظت سرمى سايتوكاين

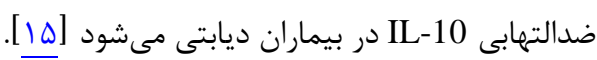
با درنظر نقشى كليدى در ياتوزنز بيمارى T2DM ايفا مى كند. طبق ديق دانش

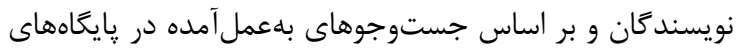

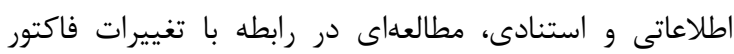

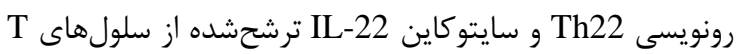

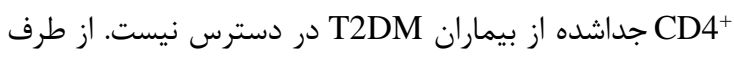

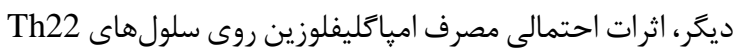

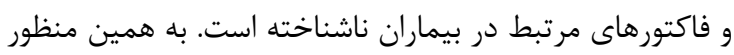
مطالعه حاضر با هدف تعيين ميزان بيان زنى فاكتور رونويسى دئي

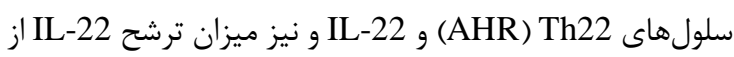
سلولهاى CD4+ T در بيماران مبتلابه T2DM انجام كرفت و

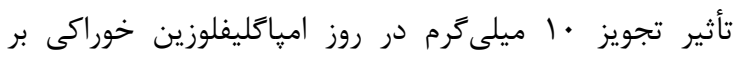

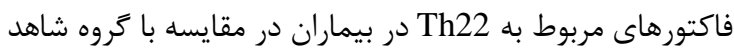




\begin{tabular}{|c|c|c|c|c|}
\hline 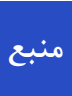 & $\begin{array}{c}\text { يرايمر معكوس } \\
5^{\prime} \text { to } 3^{\prime}\end{array}$ & 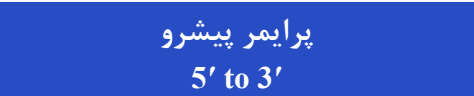 & شماره رثن & 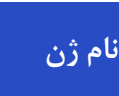 \\
\hline$[\mathrm{IV}]$ & GCTCACTCATACTGACTCCGTG & GCTTGACAAGTCCAACTTCCA & NM_020525.5 & $I L-22$ \\
\hline$[1 \wedge]$ & CCAGCAGACACCTTAGACGAC & ATACCGAAGACCGAGCTGAAT & NM_001621.5 & $A H R$ \\
\hline [19] & TTGACGGTGCCATGGAATTT & GCCATCAATGACCCCTTCATT & NM_001289746.1 & GAPDH \\
\hline
\end{tabular}

زنها استفاده شد [ع]]. يرايمرهاى استفادهشه در جدول 1

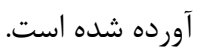

\section{كشت سلولى}

سلولهاى CD4+ T خالصشده داخل يليتهاى وه خانهاى

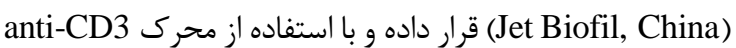

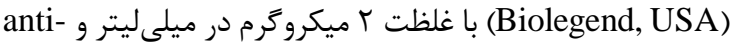

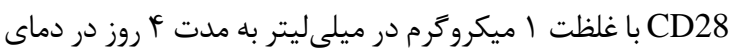

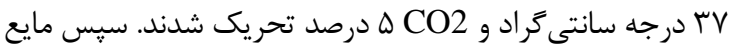

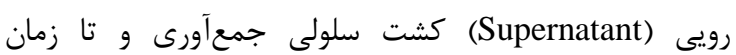
اندازهيرى ميزان IL-22 در دماى • ^- درجه نكَهدارى شد.

\section{بررسى سا يتوكا ين}

ميزان IL-22 در مايع رويى كشت سلولى با استفاده از تكنيك ين ئن

الايزا طبق دستورالعمل شركت سازنده (Biolegend, USA)

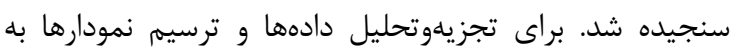

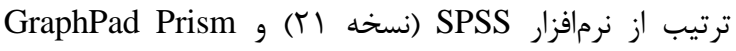

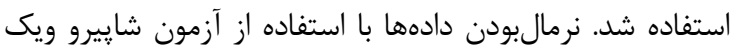

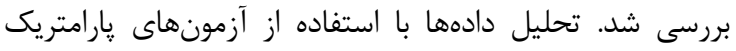

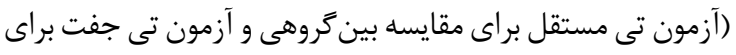

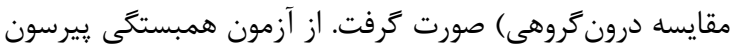

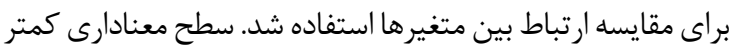

از ه • • • در نظر كرفته شد.

بافته ه.

بررسى تأثير مصرف /مياتليفلوزين بر پإرامترهاى ديابت

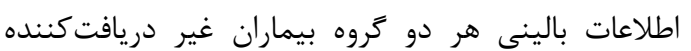

و دريافت كننده امياگليفلوزين (EMPA')

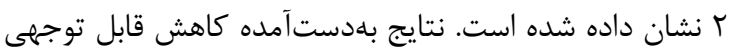

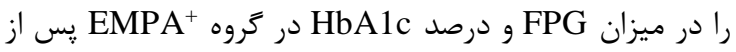

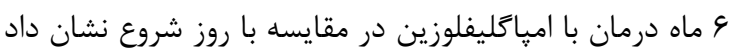

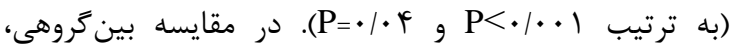

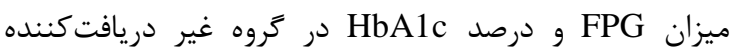
امياگليفلوزين در مقايسه با گروه دريافت كننده آن، بعد از و

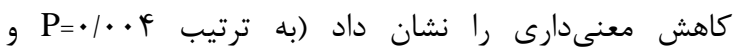

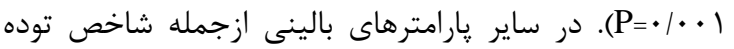

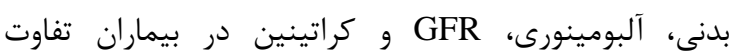

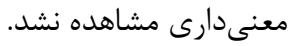

براى جداسازى PBMCها، خون كامل به نسبت 1:1 با بافر Phosphate Buffered Saline) PBS سيس بهآرامى روى فايكول استريل منتقل و به مدت • ب دقيقه

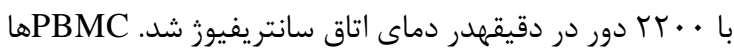
يس از جداسازى شسته و در محيط كشت سلولى حاوى

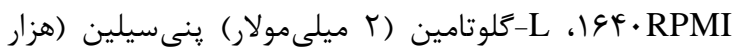

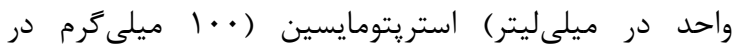

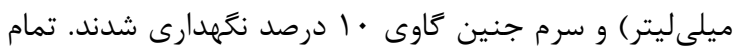

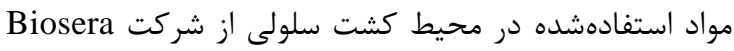
كشور فرانسه تهيه شدند.

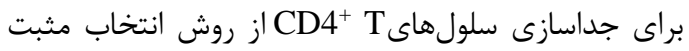

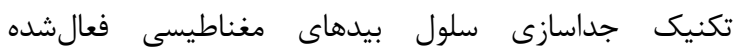
طبق يروتكل في (Magnetic activated cell sorting, MACS) كيت شركت (Miltenyi, Germany) سازنده استفاده شد. در اين روش PBMCها به مدت • • دقيقه با ميكروبيدهاى ضد

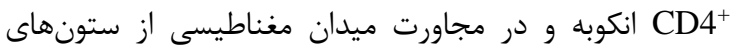
MACS استفاده در محيط كشت سلولى نكَهدارى شدند.

بروسى بيان ثرن

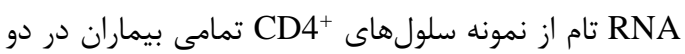

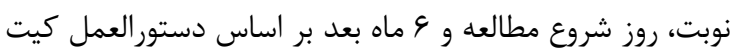
شركت سازنده (Qiagen, USA) استخر اج و غلظت آن با دستغاه

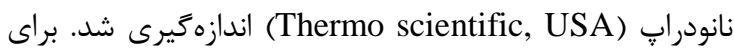
بررسى كيفيت RNA استخراجشده و نيز بهمنظور بررسى ميزان

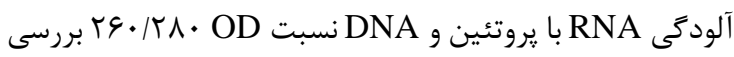

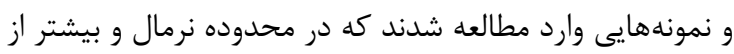

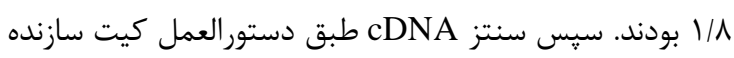
صورت گرفت. (SMOBIO, Taiwan) ارزيابى بيان زنهاى IL-22 و AHR با استفاده از تكنيك واكنش زنجيرهاى يليمراز (Real-time PCR) حاوى سايبركرين انجام شد و طبق يروتكل دمايى زير صورت زرفت: مرحلى

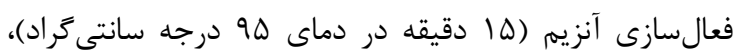

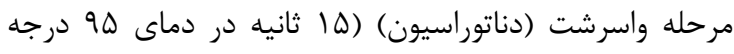

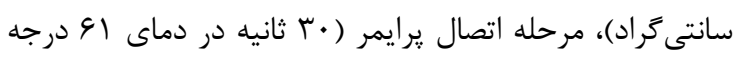

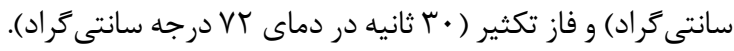
$\Delta \mathrm{Cq}=\mathrm{Cq}$ از ثن (target gene - Cq reference gene 
جدول r: مشخصات پايه گروههاى مطالعهشده

\begin{tabular}{|c|c|c|c|c|}
\hline \multicolumn{2}{|c|}{$\begin{array}{c}\text { بيماران دريافت كننده امياتليفلوزين } \\
\text { EMPA (+) }\end{array}$} & \multicolumn{2}{|c|}{$\begin{array}{c}\text { بيماران غير دريافت كننده امياكليفلوزين } \\
\text { EMPA (-) }\end{array}$} & \\
\hline و ماه بعد & روز شروع & و ماه بعد & روز شروع & \\
\hline$|r V / \Delta \varphi \pm r| / \Delta F^{a, b}$ & 19N/VG \pm rQ/VT & $|Q T / A \Lambda \pm r r / G|$ & $1 \& K / F F \pm r q / T r$ & (ميلوكز پيلاسما ناشتا \\
\hline$q|\wedge| \pm \cdot / 99 \mathrm{c}, \mathrm{d}$ & $\vee / \vee q \pm \cdot / \vee q$ & $V / T F \pm \cdot|\Lambda|$ & $\mathrm{V} / \Delta| \pm \cdot| \Lambda \Lambda$ & HaA1c \\
\hline$V F / r \Delta \pm \mid 1 / v 1$ & $V Q / 9 T \pm 19 / V T$ & $V q / \cdot q \pm \mid r / r$. & $V N / \cdot q \pm \| F / V \Delta$ & 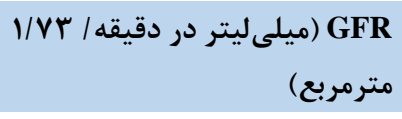 \\
\hline $\mid \Lambda / \cdot \vee \pm \Lambda / r \Lambda$ & $|G| \Lambda \mid \pm N / \Lambda T$ & $\mid F / r r \pm \varepsilon / \cdot V$ & $19 / T r \pm V / \Delta V$ & 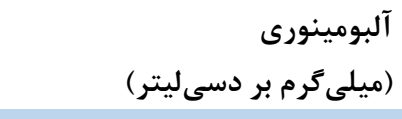 \\
\hline $.199 \pm . / 11$ & $\cdot / 9 F \pm \cdot / r r$ & $\cdot|\wedge \Lambda \pm \cdot /| \Lambda$ & $\cdot / 9 \cdot \pm \cdot / 18$ & (ميلى \\
\hline$r V / r I \pm r / q 1$ & $r V|\Lambda| \pm r / \cdot r$ & $r V / q V \pm r / A V$ & $r V / r \cdot \pm r / F r$ & (كاخلوكرم توده بدنى مترمربع) \\
\hline
\end{tabular}

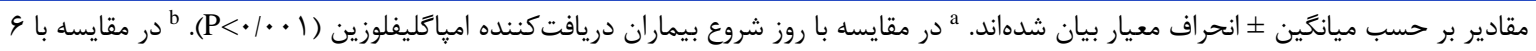

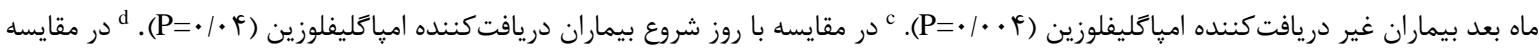

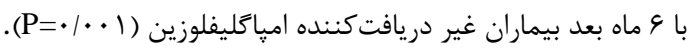

\section{بررسى تأثير مصرف /مياتليفلوزين بر ميزان ترشح}

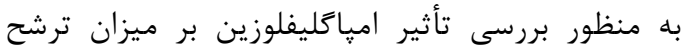

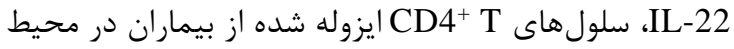
كشت سلولى تحريك و سطح IL-22 با تكنيك الايزا اندازمكيرى شد. نتايج نشان داد ميزان ترشح

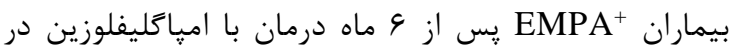

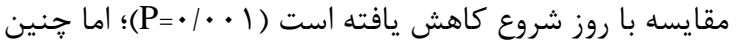
تغييرى در بيماران -EMPA مشاهده نشد. تحليل بين كروهي

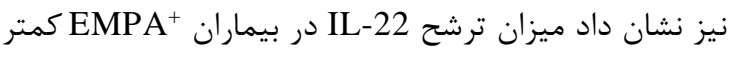

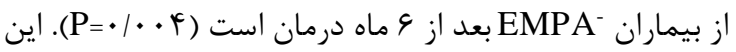

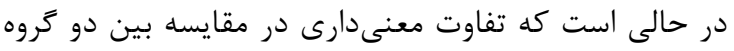
EMPA و EMPA $^{+}$

( شكل r) (1) - ( )

A

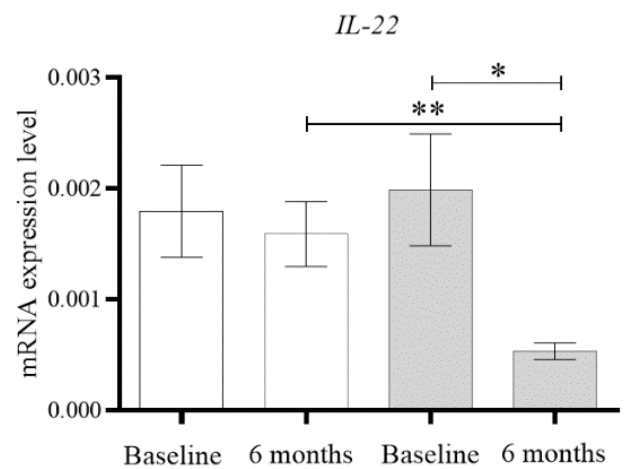

EMPA $^{-}$ $\mathrm{EMPA}^{+}$
B

بررسى تأثير مصرف /مياتليفلوزين بر بيان ثنهاى IL-22 AHR و براى بررسى تأثير امياگَليفلوزين بر بيان زنى فاكتور

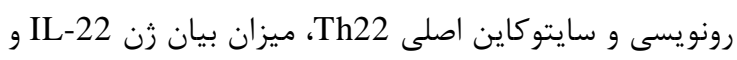

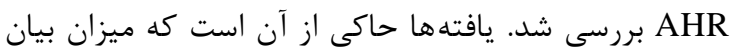

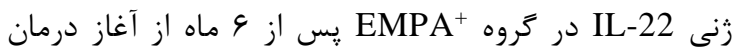
كاهش معنى دارى داشت (Baseline)

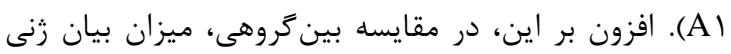

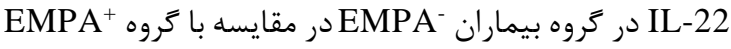

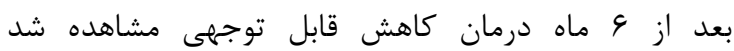

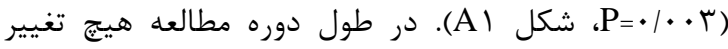

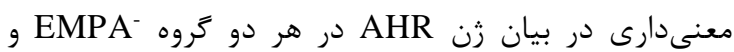
EMPA+

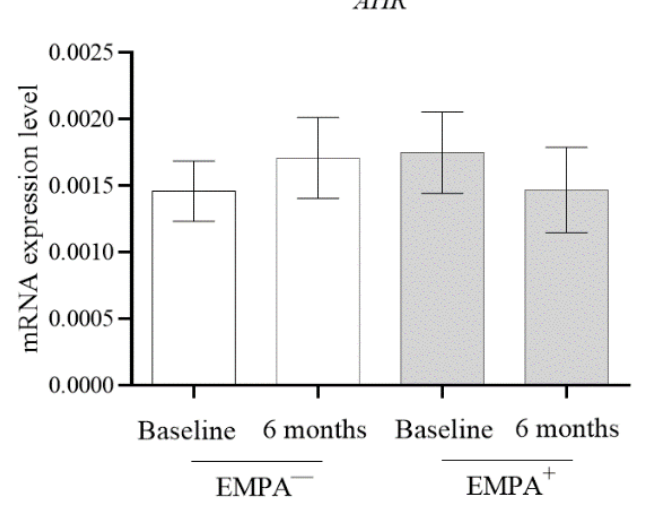

شكل ا: تأثير مصرف امياكَليفلوزين بر بيان رنهاى AHR و IL-22 
بررسى همبستتسى بين AHR و IL و پإرامترهاى ديابت

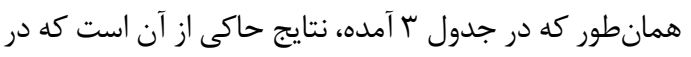

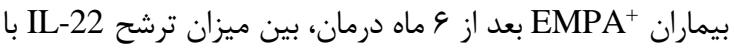

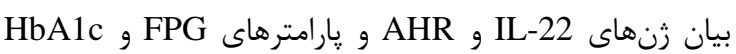

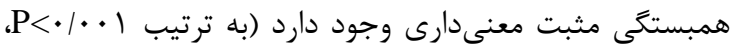

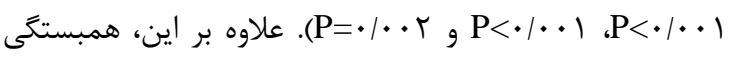
مثبت معنى دارى ميان بيان رنى IL-22 با بيان AHR و

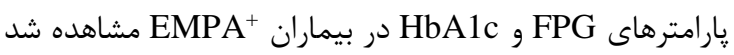

( $\mathrm{P}=\cdot / \cdot \boldsymbol{F}, \mathrm{P}<\cdot / \cdots) ، \mathrm{P}<\cdot / \cdot \cdot 1)$
Supernatant IL-22

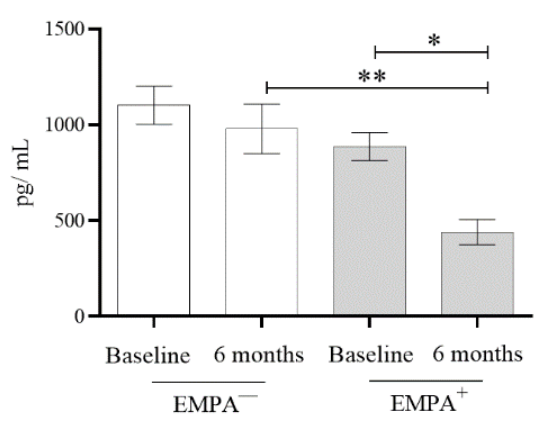

شكل rا: بررسى تأثير مصرف امياگليفلوزين بر ميزان ترشح IL-22

جدول "ا: همبستكى بين متغيرهاى مطالعهشه در بيماران دريافت كننده امياكليفلوزين بعد از 9 ماه

\begin{tabular}{|c|c|c|c|c|c|}
\hline درصد HbA1c & ميزان FPG & ميزان بيان ثن AHR & ميزان بيان ثن IL-22 & & \\
\hline $\begin{array}{l}\cdot 1 \Delta V \\
\cdot / \cdot r\end{array}$ & $\begin{array}{l}\cdot / \wedge V \\
<\cdot / \cdot \cdot \mid\end{array}$ & $\begin{array}{c}\cdot / V \Delta \\
<\cdot / \cdot \cdot 1\end{array}$ & $\begin{array}{c}\cdot / 94 \\
<\cdot 1 \cdot \cdot 1\end{array}$ & عدد ع ع Pد P & ميزان ترشح IL-22 \\
\hline $\begin{array}{l}\cdot 10 \Delta \\
\cdot 1 \cdot r F\end{array}$ & $\begin{array}{c}\cdot 119 \\
<\cdot 1 \cdot \cdot 1\end{array}$ & $\begin{array}{c}\cdot / V V \\
<\cdot / \cdot \cdot 1\end{array}$ & - & عدد r عد P & ميزان بيان ثن IL-22 \\
\hline
\end{tabular}

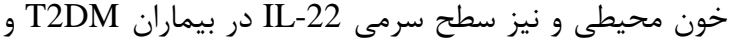

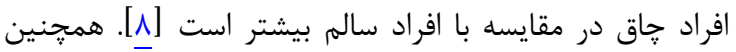

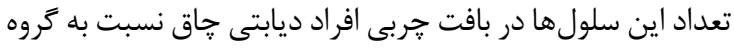
كنترل افزايش داشته است [• [1].

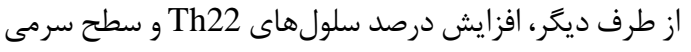

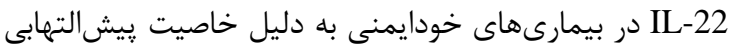

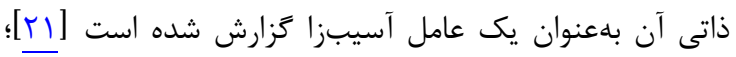

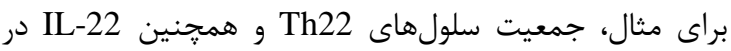
بيماران مبتلابه بيمارى لويوس اريتماتوز سيستميك در مقايسه

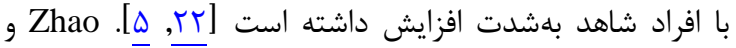

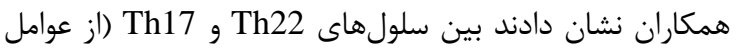
ديخر مؤثر در التهاب) همبستخى مثبتى وجود دارد [هـ]. علاوه بر

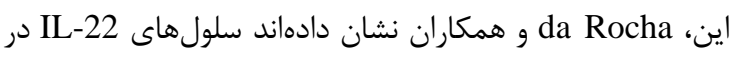
خون محيطى بيماران مبتلابه روماتوئيد آرتريت افزايش داشندان داشته

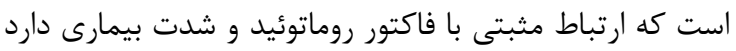

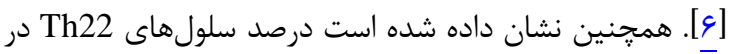

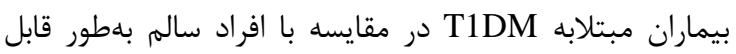

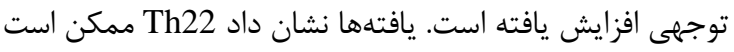

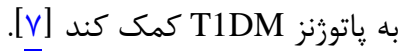
با توجه به مطالب عنوانشده، افزايش فاكتورهاى مربوط به

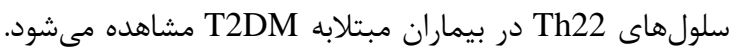

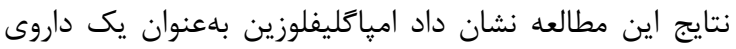

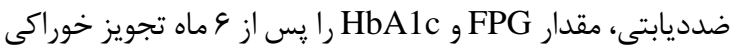
كاهش مى دهد. همجنين مصرف داروى امياكليفلوزين به مدت

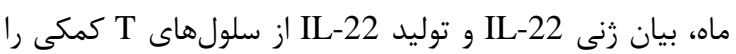
كاهش داد. ميزان بيان زنى و توليد IL-22 با بيان فاكتور
مطالعات پِيشين شواهدى محكم مبنى بر عدم تنظيم مناسب

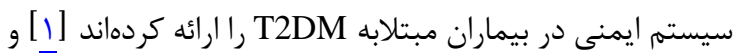

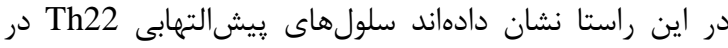

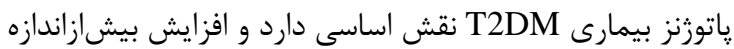

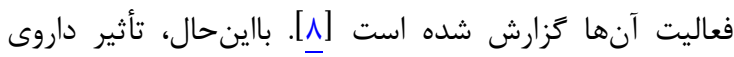

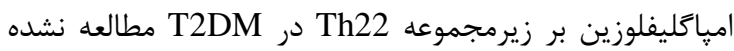
است. مطالعه حاضر با هدف تعيين تغييرات فاكتورهاى رونويسى

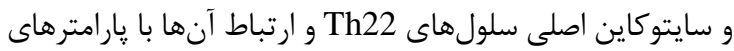

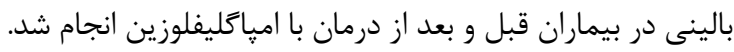

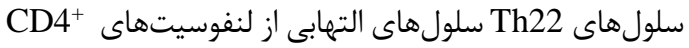

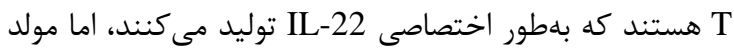

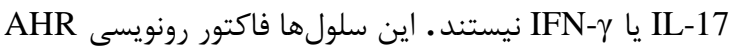

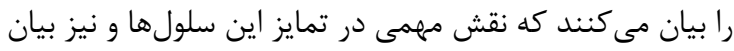

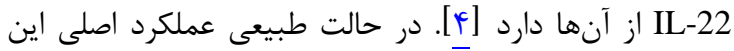

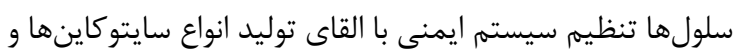

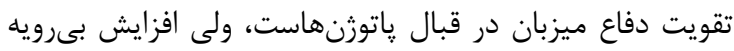

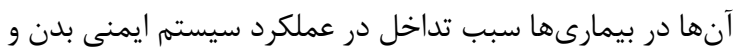

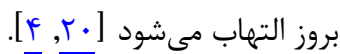
برخى از مطالعات شواهدى ارائه دادهاند كه نشان مى مىهد

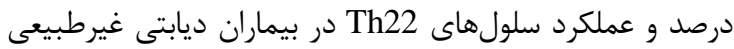

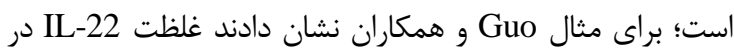

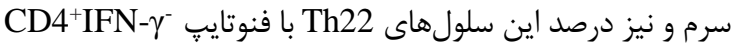
IL-17A-IL-22+ با افراد سالم بيشتر است و ارتباط مستقيمى با شاخص مقاومت دئمارن

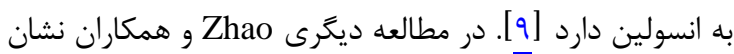

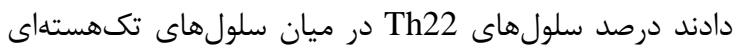


مانند Th1 Th17، Th1 Th9 و Th2 بر Th2 برسى كنند. همجنين در اين مطالعه IL-22 در مايع رويى كشت سلولهاى

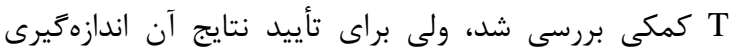

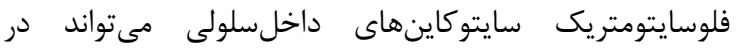
تحقيقات آينده صورت يذيرد. علاوه بر اين، در تحقيقات آينده

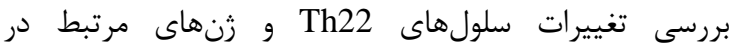
زيرگروههاى مختلف بيمارى مانند نفروياتى ديابتى، رتينوياتى ني

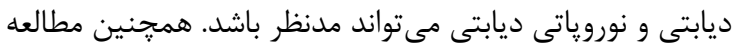

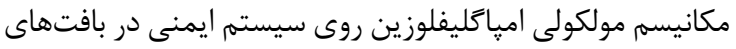

مرتبط با ديابت مثل يانكراس مىتواند مورد توجه قرار كيرد.

\section{نتيجه تيرى}

در اين مطالعه، خواص ضدالتهابى مصرف ماري ماروى

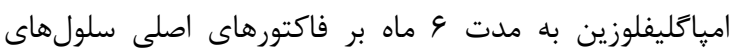

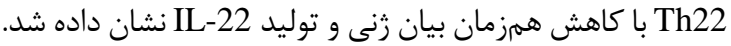
از طرف ديخر، همبستخى مثبتى ميان IL-22 با بيان زنى فاكتور رونويسى سلولهاى (AHR) Th22 مشاهده شد. در بيماران

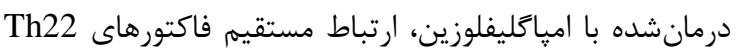

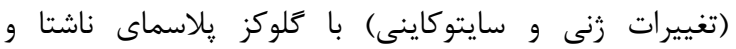

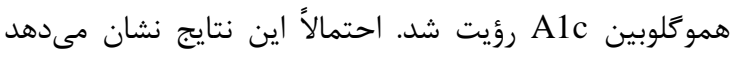

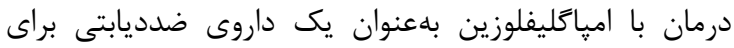

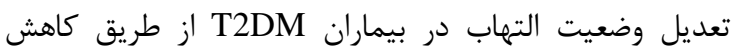
Th22

\section{تشكر و قدر دانى} اين مقاله بركرفته از ياياننامه دوره كارشناسى ارشد

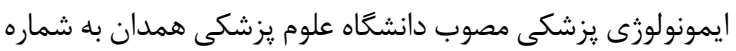

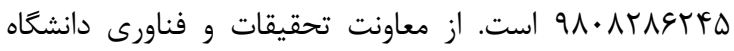

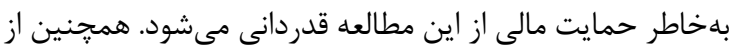

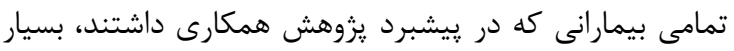
سياسگزارى مى كنيه.

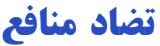

نتايج اين مطالعه با منافع نويسندًان تعارض ندارد.

\section{ملاحظات اخلاقى}

اين يروزه در كميته اخلاق دانشگاه علوم يزشكى همدان با كد اخلاق IR.UMSHA.REC.1398.648 تصويب شده است.

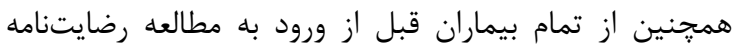

آكاهانه كتبى گرفته شده است.

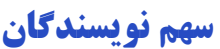

نويسنده اول: (يزوهشكر اصلى) تدوين يرويوزال، انجام

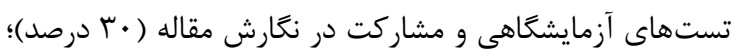

رونويسى AHR و پِارامترهاى بالينى (FPG و HbA1c) رابطه مثبت معنى دارى داشت. در اين مطالعه هر دو گروه دريافت كننده

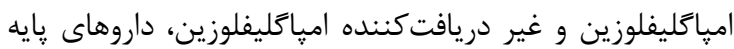
متفورمين و كَليكلازيد را با دُز يكسان دريافت كردند. اين در درائ

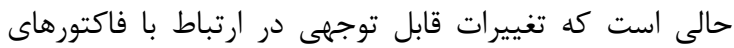

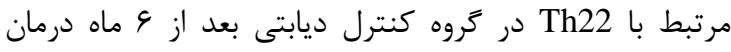

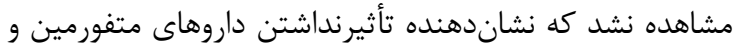
كليكلازيد بر سلولهاى ذكرشده است.

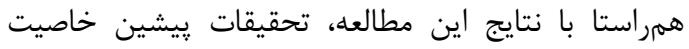

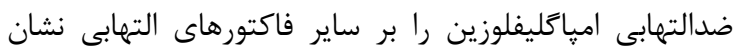

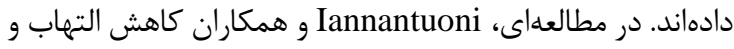

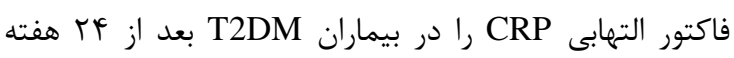

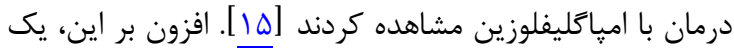

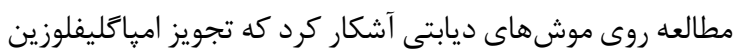

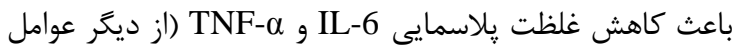

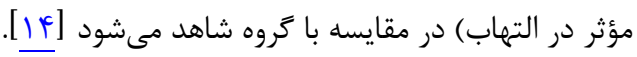
يافتههاى قبلى نشان دادهاند IL-22 نقش فعالى در التهاب

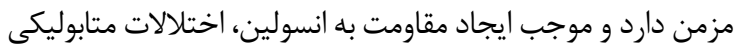

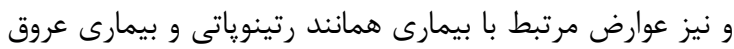

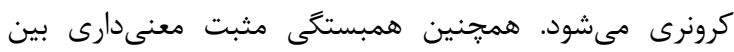

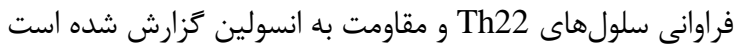

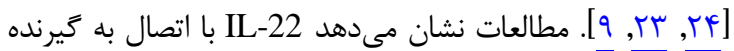
خود و فعالسازى يروتئينهاى Signal transducers and (STAT3) activators of transcription 3

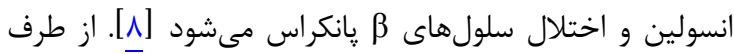
ديغر، برخى از مطالعات به شواهدى اشاره كردهاند كه نشان إنى

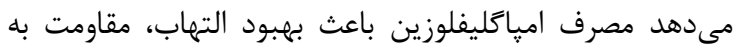

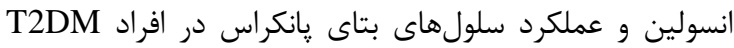

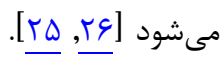
بالينوجود مطالعه حاضر صرفاً اثرات ضدالتهابى داروى امياكليفلوزين را بر فاكتورهاى مرتبط با سلول هاى Th22 آشكار

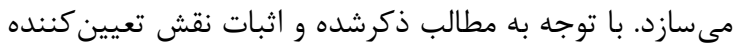

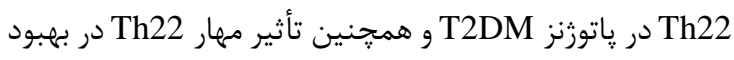
التهاب و وجود ارتباط مستقيه بين كاهش

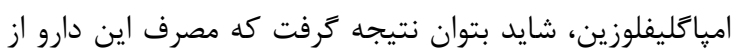
طريق كاهش فاكتورهاى مرتبط با Th22 (در كنار كاهش كلوكز

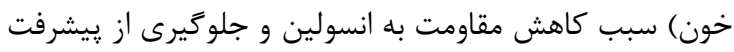
بيمارى مىشود. بالين حال، ارزيابى هاى بيشترى در زمينه اثرات

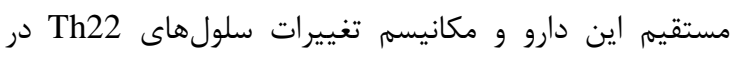

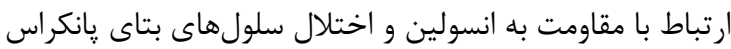
نياز است. از محدوديتهاى اين مطالعه اينكه در اين طرح صرفاً اثر

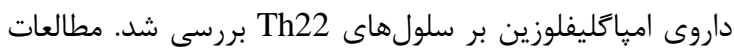

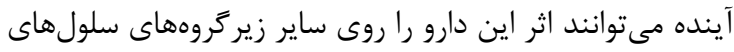




$$
\text { تحليل هاى آمارى، نعارش مقاله (·r درصد). }
$$

\section{REFERENCES}

1. Zhou T, Hu Z, Yang S, Sun L, Yu Z, Wang G. Role of adaptive and innate immunity in type 2 diabetes mellitus. $J$ Diabetes Res. 2018;2018:7457269. PMID: 30533447 DOI: $10.1155 / 2018 / 7457269$

2. Calle MC, Fernandez ML. Inflammation and type 2 diabetes. Diabetes Metab. 2012;38(3):183-91. PMID: 22252015 DOI: 10.1016/j.diabet.2011.11.006

3. Kagami S, Rizzo HL, Lee JJ, Koguchi Y, Blauvelt A. Circulating Th17, Th22, and Th1 cells are increased in psoriasis. J Invest Dermatol. 2010;130(5):1373-83. PMID: 20032993 DOI: $10.1038 /$ jid.2009.399

4. Jia L, Wu C. The biology and functions of Th22 cells. Adv Exp Med Biol. 2014;841:209-30. PMID: 25261209 DOI: 10.1007/978-94-017-9487-9_8

5. Zhao L, Jiang Z, Jiang Y, Ma N, Wang K, Zhang Y, et al. IL$22+\mathrm{CD} 4+\mathrm{T}$-cells in patients with active systemic lupus erythematosus. Exp Biol Med (Maywood). 2013;238(2):1939. PMID: 23576801 DOI: $10.1177 / 1535370213477597$

6. da Rocha LF Jr, Duarte AL, Dantas AT, Mariz HA, Pitta Ida $\mathrm{R}$, Galdino SL, et al. Increased serum interleukin 22 in patients with rheumatoid arthritis and correlation with disease activity. J Rheumatol. 2012;39(7):1320-5. PMID: 22589261 DOI: $10.3899 /$ irheum.111027

7. Xu X, Zheng S, Yang F, Shi Y, Gu Y, Chen H, et al. Increased Th22 cells are independently associated with Th17 cells in type 1 diabetes. Endocrine. 2014;46(1):90-8. PMID: 23928796 DOI: $10.1007 / \mathrm{s} 12020-013-0030-\mathrm{Z}$

8. Zhao R, Tang D, Yi S, Li W, Wu C, Lu Y, et al. Elevated peripheral frequencies of Th22 cells: a novel potent participant in obesity and type 2 diabetes. PLoS One. 2014;9(1):e85770. PMID: 24465695 DOI: 10.1371/journal.pone.0085770

9. Guo H, Xu BC, Yang XG, Peng D, Wang Y, Liu X B, et al. A high frequency of peripheral blood IL-22(+) CD4(+) T cells in patients with new onset type 2 diabetes mellitus. $J$ Clin Lab Anal. 2016;30(2):95-102. PMID: 25425169 DOI: 10.1002/jcla.21821

10. Dalmas E, Venteclef N, Caer C, Poitou C, Cremer I, AronWisnewsky J, et al. T cell-derived IL-22 amplifies IL-1 $\beta$ driven inflammation in human adipose tissue: relevance to obesity and type 2 diabetes. Diabetes. 2014;63(6):1966-77. PMID: 24520123 DOI: 10.2337/db13-1511

11. Fujita Y, Inagaki N. Metformin: new preparations and nonglycemic benefits. Curr Diab Rep. 2017;17(1):5. PMID: 28116648 DOI: $10.1007 / \mathrm{s} 11892-017-0829-8$

12. Araújo AA, Morais HB, Medeiros C, Brito GA, Guedes PM, Hiyari S, et al. Gliclazide reduced oxidative stress, inflammation, and bone loss in an experimental periodontal disease model. J Appl Oral Sci. 2019;27:e20180211. PMID: 30810635 DOI: 10.1590/1678-7757-2018-0211

13. Frampton JE. Empagliflozin: a review in type 2 diabetes. Drugs. 2018;78(10):1037-48. PMID: 29946963 DOI: $10.1007 / \mathrm{s} 40265-018-0937-\mathrm{z}$

14. Han JH, Oh TJ, Lee G, Maeng HJ, Lee DH, Kim KM, et al. The beneficial effects of empagliflozin, an SGLT2 inhibitor, on atherosclerosis in ApoE (-/-) mice fed a western diet. Diabetologia. 2017;60(2):364-76. PMID: 27866224 DOI: $10.1007 / \mathrm{s} 00125-016-4158-2$

$$
\begin{aligned}
& \text { نويسنده دوم: (يزوهشكر همكار) مشاور علمى، معرفى بيماران، }
\end{aligned}
$$

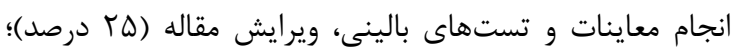

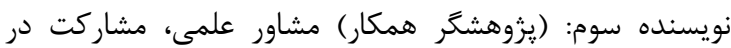

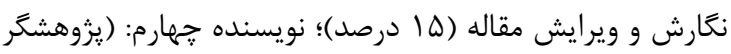

$$
\begin{aligned}
& \text { اصلى) مسئول مكاتبات، طراحى يروزه، اجراو نظارت بر آن، انجام }
\end{aligned}
$$

15. Iannantuoni F, Diaz-Morales N, Falcon R, Bañuls C, AbadJimenez Z, Victor VM, etal. The SGLT2 inhibitor empagliflozin ameliorates the inflammatory profile in type 2 diabetic patients and promotes an antioxidant response in leukocytes. J Clin Med. 2019;8(11):1814. PMID: 31683785 DOI: $10.3390 / \mathrm{jcm} 8111814$

16. Telikani Z, Sheikh V, Zamani A, Borzouei S, Salehi I, Amirzargar MA, et al. Effects of sitagliptin and vitamin D3 on $\mathrm{T}$ helper cell transcription factors and cytokine production in clinical subgroups of type 2 diabetes mellitus: highlights upregulation of FOXP3 and IL-37. Immunopharmacol Immunotoxicol. 2019;41(2):299-311. PMID: 30907193 DOI: 10.1080/08923973.2019.1593447

17. Jiang R, Wang H, Deng L, Hou J, Shi R, Yao M, etal. IL-22 is related to development of human colon cancer by activation of STAT3. BMC Cancer. 2013;13:59. PMID: 23379788 DOI: 10.1186/1471-2407-13-59

18. Cheng L, Qian L, Tan Y, Wang GS, Li XM, Li XP, et al. Unbalanced expression of aryl hydrocarbon receptor in peripheral blood CCR6(+)CD4(+) and CD4(+)CD25(+) T cells of rheumatoid arthritis. Rev Bras Reumatol Engl Ed. 2017;57(3):190-6. PMID: 28535889 DOI: 10.1016/j.rbre. 2016.07.002

19. Hoseini-Aghdam M, Sheikh V, Eftekharian MM, Rezaeepoor M, Behzad M. Enhanced expression of TIGIT but not neuropilin-1 in patients with type 2 diabetes mellitus. Immunol Lett. 2020;225:1-8. PMID: 32540486 DOI: 10.1016/j.imlet.2020.06.003

20. Sabat R, Ouyang W, Wolk K. Therapeutic opportunities of the IL-22-IL-22R1 system. Nat Rev Drug Discov. 2014;13(1):21-38. PMID: 24378801 DOI: $10.1038 / \mathrm{nrd} 4176$

21. Azizi G, Yazdani R, Mirshafiey A. Th22 cells in autoimmunity: a review of current knowledge. Eur Ann Allergy Clin Immunol. 2015;47(4):108-17. PMID: 26159476

22. Zhong W, Jiang Y, Ma H, Wu J, Jiang Z, Zhao L. Elevated levels of CCR6(+) T helper 22 cells correlate with skin and renal impairment in systemic lupus erythematosus. Sci Rep. 2017;7(1):12962. PMID: 29021537 DOI: $10.1038 / \mathrm{s} 41598-$ 017-13344-w

23. Chen H, Wen F, Zhang X, Su SB. Expression of T-helperassociated cytokines in patients with type 2 diabetes mellitus with retinopathy. Mol Vis. 2012;18:219-26. PMID: 22312190

24. Gong F, Wu J, Zhou P, Zhang M, Liu J, Liu Y, et al. Interleukin-22 might act as a double-edged sword in type 2 diabetes and coronary artery disease. Mediators Inflamm. 2016;2016:8254797. PMID: 27829708 DOI: 10.1155/ 2016/8254797

25. Ferrannini E, Muscelli E, Frascerra S, Baldi S, Mari A, Heise $\mathrm{T}$, et al. Metabolic response to sodium-glucose cotransporter 2 inhibition in type 2 diabetic patients. J Clin Invest. 2014;124(2):499-508. PMID: 24463454 DOI: 10.1172/ jici72227

26. Al Jobori H, Daniele G, Adams J, Cersosimo E, Solis-Herrera $\mathrm{C}$, Triplitt $\mathrm{C}$, etal. Empagliflozin treatment is associated with improved $\beta$-cell function in type 2 diabetes mellitus. J Clin Endocrinol Metab. 2018;103(4):1402-7. PMID: 29342295 DOI: $10.1210 /$ jc. $2017-01838$ 